\title{
E-Learning at Private Universities in Kurdistan Region: A Comparative Field Study
}

\author{
Adnan Fadhil \\ Head of General Education Department, College of Education and Languages, \\ Lebanese French University, Erbil, Kurdistan Region, Iraq \\ Email: afk.lfu@gmail.com \\ Zohair Al-Ameen \\ Department of General Education, College of Education and Languages, \\ Lebanese French University, Erbil, Kurdistan Region, Iraq \\ Email: qizohair@lfu.edu.krd
}

\begin{abstract}
Higher education is encountering major alteration in many countries. As well, many innovative learning techniques are emerging due to the speedy growths of technology, internet and communication tools. This thrive of technology has changed various features and conceptions of the traditional learning environments. Recently, the attention has focused on electronic learning (e-learning), which is a form of education that has begun to find its way into different developing countries due to its high potential in improving the educational process. However, different real-world challenges emerged, in which they hampered the application of e-learning in developing countries. Thus, this study aims to identify the status of the actual level of e-learning application among private universities in the Kurdistan region of Iraq. It is believed that the results of this study will greatly ameliorate the currently utilized educational systems.
\end{abstract}

Index Terms - Comparative studies, e-learning, learning systems, modern technologies, private universities.

\section{INTRODUCTION}

The increased utilization of internet and technology in the practice of education is a worldwide trend. Electronic learning (e-learning) is one of the first fields that focused on the inclusion of internet and modern technology in educational systems [1]. E-learning can be defined as the process of learning that depends on technology and involves the use of software programs and computer devices [2]. E-learning was first introduced with the intention of helping students who cannot access proper full-time education. Such group of students comprises people who are interested in studying while working simultaneously. Today, the use of e-learning has extended to cover all types of university students, whether they are part-time, full-time or distance learning students [3]. In general, developed countries are strikingly more advanced than developing countries in the educational achievements.

A contemporary trend that emerged in the higher education practices of developed countries is the utilization of different e-learning systems to provide various students with online access to up-to-date learning materials [4]. However, the use of e-learning in developing countries encounters many significant challenges, among which is the lack of important elements such as electricity, computers, required skills and the actual contribution of students and educators. Elearning can compensate the drawbacks of the traditional education methods at private universities and allow educators to communicate information to a reasonably huge number of students despite the limitation of time, space or facilities [5]. For these reasons, many researchers studied the issues related to e-learning application in developing countries so that they can contribute to the improvement of the current educational processes.

These researchers introduced many research works addressed in Section II. Various initiatives have been made to implement the appropriate practice of e-learning at private universities in the Kurdistan region of Iraq. However, only little information is known regarding these procedures, applications and the success factors of e-learning. In addition, research studies on e-learning implementation in Kurdistan are very limited. Hence, this study aims to identify the status of the actual level of elearning application within private universities in the Kurdistan region of Iraq. To achieve this aim, an in-depth research is undertaken to investigate the possibility of utilizing this modern technique.

In addition, the data of this study was collected from 4 private universities in Erbil; namely, Cihan, Al-Hayat, Ishik and the Lebanese French (LFU), wherein 25 samples were considered from each university. Within this context, this research is considered important since it endeavors to improve e-learning applications in Kurdistan; thus, reducing the failure possibilities due to inexperience in e-learning needs and the apprehensions of various e-learning beneficiaries. Moreover, the results of this study will serve to ameliorate the currently utilized education systems. The article is structured as follows: in Section II, the related research works on e-learning and private universities are addressed. In Section III, the used 
survey tool is provided. In Section IV, the related information on methodology is identified. In Section V, the important findings and their related discussions are presented. Finally, a vital conclusion is given in Section VI.

\section{RELATED WORKS}

In this section, the related research works on e-learning and private universities are addressed. In [6], the authors aimed to scrutinize the situation of e-learning in Korea in order to come up with new methods that promote the employment and improvement of e-learning systems. A total of 201 private and public universities in Korea were examined for the purpose of this study. In [7], the authored aimed at identifying the positive factors involved in applying many e-learning programs in Malaysia by studying various research works on this topic. In [8], the authors tried to identify problems related to e-learning via feedback obtained from students in various Pakistani private universities, where many issues were highlighted via extensive reviews and discussions with various students.

In [9], the authors tried to assess the influence of elearning on the education systems in Kurdistan, where the authors used an online questionnaire that involved many educators and students. In [10], the authors tried to determine the parameters of interactivity, e-learning significance, comfortability, familiarity, and student satisfaction with e-learning at private universities in Egypt. In [11], the authors attempted to demonstrate how the use of interactive traits of e-learning can improve the learning motivation of undergraduate students. It is a fact that the private universities have to cater well for their students. This calls for innovation, as the utilization of elearning offers this opportunity. Finally, adopting elearning requires thorough understanding of the requirements and restrictions in the e-learning platform.

\section{SURVEY TOOL}

Proper data collection is important to any comparative study. In fact, no study can give meaningful outcomes without the collection of proper data. Hence, the method of data collection for this study is based on questionnaires administered by the researchers at different private universities in Erbil. It is necessary to use a proper tool to gather information on the following e-learning aspects:

1. The use of electronic devices in the process of elearning.

2. The purposes of using e-learning.

3. The use of subordinate applications with e-learning.

Information on the aspects above was obtained from academia that have experience in teaching students at private universities utilizing e-learning, and from the practical experience of the researchers. The tool applied is the following questionnaire:
A- The use of electronic devices in the process of $e$ learning.

1. Are desktop computers used in the e-learning process?

$$
\text { ( ) Yes ( ) No }
$$

2. Are laptop computers indispensable in the elearning process?

$$
\text { ( ) Yes ( ) No }
$$

3. Do you think that it is necessary to use a tablet computer in the e-learning process?

( ) Yes ( ) No

4. Is the smart board being used at your university? ( ) Yes ( ) No

5. Is your smart phone being used in the e-learning process?

$$
\text { ( ) Yes ( ) No }
$$

$B$ - The purposes of using e-learning:

1. Is e-learning embedded in your classroom activities effectively?

$$
\text { ( ) Yes ( ) No }
$$

2. Do you employ e-learning in extracurricular activities?

$$
\text { ( ) Yes ( ) No }
$$

3. Do you utilize e-learning in the process of selflearning?

( ) Yes ( ) No

4. Does e-learning further enhance your learning abilities through social media?

$$
\text { ( ) Yes ( ) No }
$$

5. Does e-learning increase your chances to learn more through online materials?

$$
\text { ( ) Yes ( ) No }
$$

C- The use of subordinate applications with e-learning.

1. Do you have an electronic application that you employ to calculate your coursework grades?

$$
\text { ( ) Yes ( ) No }
$$

2. Do you have an electronic application that you use to organize your daily timetable?

$$
\text { ( ) Yes ( ) No }
$$

3. Do you calculate your absence rates through a specific electronic application?

$$
\text { ( ) Yes ( ) No }
$$

\section{MethodOLOGY}

In this section, information related methodology is presented. In addition, a quantitative methodology is used in this study since it is efficient and acceptable by most researchers [12]. Furthermore, it can give more meaningful information which contributes to attaining the purposes of this study [13]. It is known that various renowned comparative methods are available; they are investigated to determine the one that is applicable to this study. It is found out that Bereday's method [14] is the most suitable since it is presumed to be as one of the finest schematized methods in the field of comparative 
education [15]. Bereday's comparative method consists of four distinct stages:

1. Data Collection and Description: at this stage, informative data designated for the study is gathered and demonstrated in a descriptive manner to simplify additional analysis at other stages.

2. Interpretation: at this stage, the analysis of the obtained information using techniques from diverse social sciences is involved. In addition, many associated factors can be utilized to clarify the questions that are raised or the ones that influence the educational system.

3. Juxtaposition: at this stage, initial comparisons among many aspects such as concepts, findings, facts and principles are made to organize and process data. Moreover, it is possible to set out the comparability standards throughout this stage.

4. Comparison: this is the last stage, which contains a final data fusion for the purpose of assessment and setting the strategies for action.

It is worth mentioning that the current research society includes various students of the aforesaid private universities in the province of Erbil, for the academic year 2015-2016. Furthermore, the researchers applied their tool on 100 students; 25 from each university. After that, the answers of the students were collected and then processed to determine the results. Moreover, the data of this study was gathered from students that have experience in using e-learning. Finally, the analysis of the gathered data was carried out manually.

\section{RESUlTS AND DISCUSSION}

In this section, the important findings and their related discussions are reported. With respect to the first aspect which contains questions about the use of electronic devices in the process of e-learning, the results are presented in Table 1 and Fig. 1. Regarding the use of desktop computers, the ratios were somewhat low in all universities because such devices are not popular among students; they are mainly used in the lab sessions. Regarding laptop computers, the ratios were relatively high. Cihan University scored the highest. It is the researchers' conviction that this is due to the personal nature of the students. Regarding tablet computers, the ratios were very low compared to those involving other devices.

Table 1. The use of electronic devices for e-learning.

\begin{tabular}{|l|l|c|c|c|c|}
\hline \multirow{2}{*}{\multicolumn{2}{|c|}{ Devices }} & \multicolumn{4}{c|}{ Universities / Ratios } \\
\cline { 3 - 6 } \multicolumn{2}{|c|}{} & LFU & Cihan & Ishik & al-Hayat \\
\hline 1 & Desktop Computers & $24 \%$ & $32 \%$ & $20 \%$ & $16 \%$ \\
\hline 2 & Laptop Computers & $76 \%$ & $96 \%$ & $60 \%$ & $17 \%$ \\
\hline 3 & Tablet Computers & $16 \%$ & $20 \%$ & $10 \%$ & $17 \%$ \\
\hline 4 & Smart Boards & $0 \%$ & $16 \%$ & $51 \%$ & $0 \%$ \\
\hline 5 & Smart Phones & $56 \%$ & $40 \%$ & $30 \%$ & $61 \%$ \\
\hline
\end{tabular}

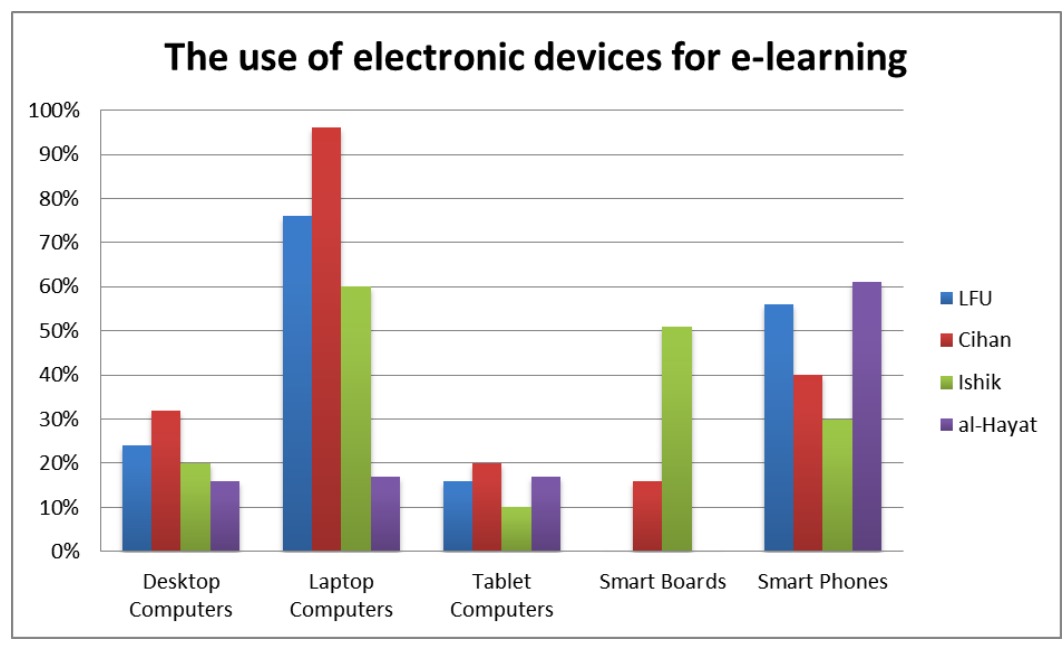

Fig.1. The analytical chart of Table 1.

This may be due to the lack of acquisition of such device, as its applications are very much similar to those of smart phone devices. Regarding the smart board, Ishik University was the best in using this technology; the difference is huge when compared to other universities. This is an indication that this university offers its students advanced educational schemes, which reflects positively on the performance of its students. Regarding smart phones, it is noted that the use of such device in elearning is acceptable at al-Hayat and the Lebanese French Universities. Furthermore, Cihan University approached the ratio of acceptance, but Ishik University 
came up weak, which explains the lack of desire for Ishik students to use such device in education. Concerning the overall use of electronic devices in all universities, the results are displayed in Table 2 and Fig. 2.

Table 2. The use of electronic devices in all universities.

\begin{tabular}{|l|l|c|}
\hline$\#$ & Devices & Ratios \\
\hline 1 & Laptop Computers & $63 \%$ \\
\hline 2 & Smart Phones & $47 \%$ \\
\hline 3 & Desktop Computers & $23 \%$ \\
\hline 4 & Smart Boards & $17 \%$ \\
\hline 5 & Tablet Computers & $16 \%$ \\
\hline
\end{tabular}

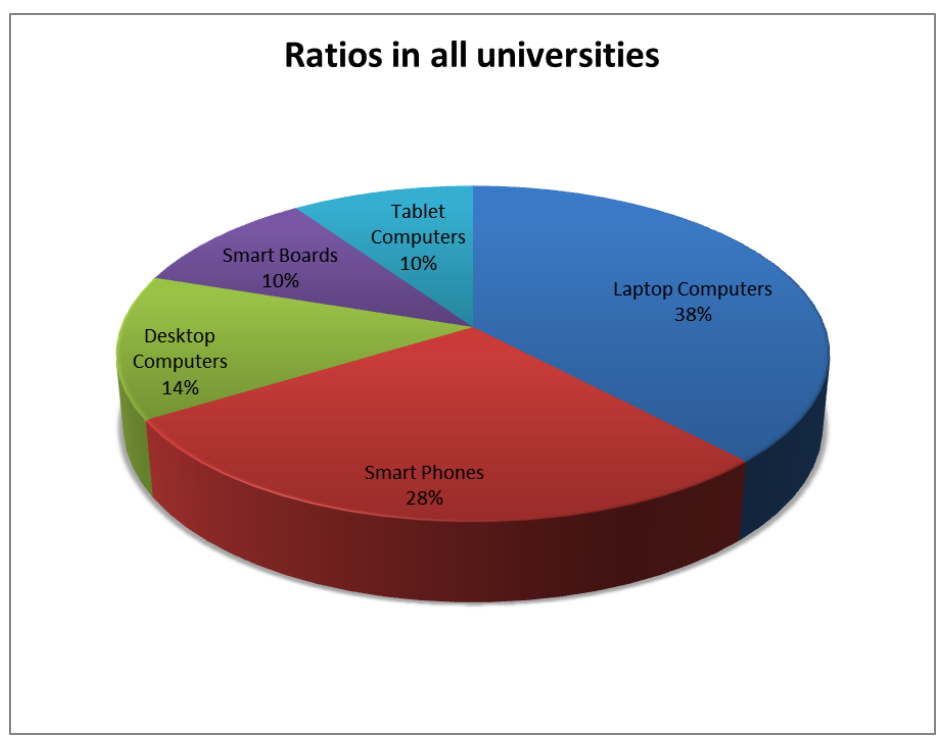

Fig.2. The analytical chart of Table 2.

Table 3. The purposes of using e-learning.

\begin{tabular}{|c|l|c|c|c|c|}
\hline \multirow{2}{*}{\multicolumn{2}{|c|}{ Purposes }} & \multicolumn{4}{c|}{ Universities / Ratios } \\
\cline { 3 - 6 } & LFU & Cihan & Ishik & al-Hayat \\
\hline 1 & Classroom Activities & $28 \%$ & $20 \%$ & $50 \%$ & $5 \%$ \\
\hline 2 & Extracurricular Activities & $68 \%$ & $12 \%$ & $27 \%$ & $5 \%$ \\
\hline 3 & Self-Learning & $48 \%$ & $44 \%$ & $23 \%$ & $28 \%$ \\
\hline 4 & Social Media & $66 \%$ & $72 \%$ & $32 \%$ & $39 \%$ \\
\hline 5 & Online Materials & $28 \%$ & $26 \%$ & $9 \%$ & $27 \%$ \\
\hline
\end{tabular}

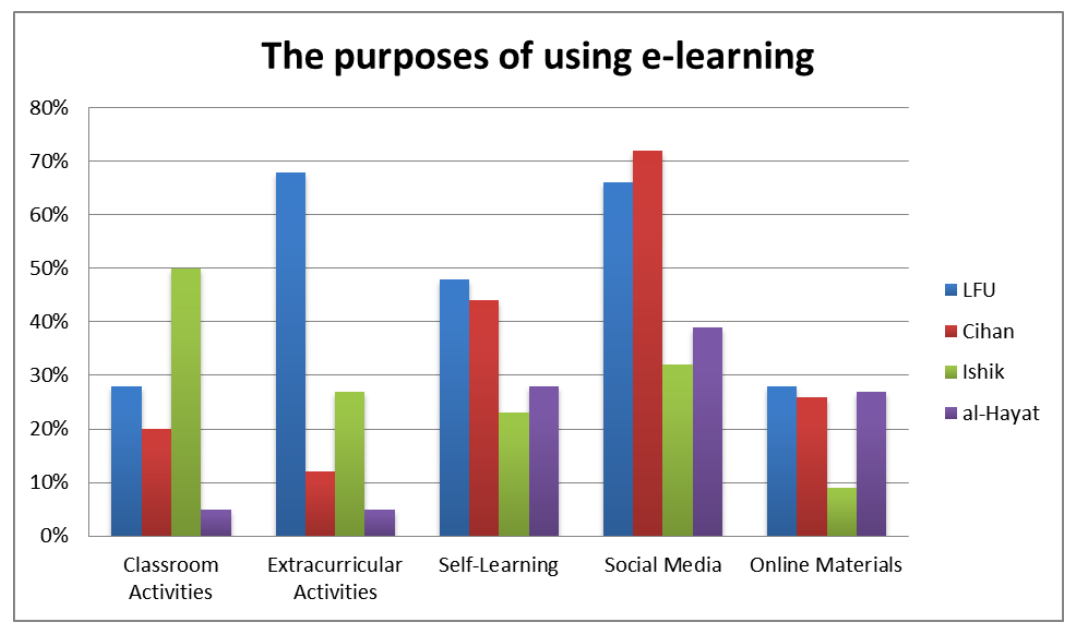

Fig.3. The analytical chart of Table 3. 
With respect to the second aspect, which contains questions on the purposes of using e-learning, the results are revealed in Table 3 and Fig. 3. Regarding classroom activities, the findings were dissimilar. Ishik University scored the best due to the right utilization of modern technology in their classrooms when compared to other universities. Moreover, the convergence of ratios between Cihan and the Lebanese French universities was noticeable, but it did not reach the anticipated level. On the other hand, al-Hayat University scored the lowest, which may be due to the weak orientations of students in the use of e-learning technology in their classrooms. Regarding extracurricular activities, the highest ratio was scored by the students of the Lebanese French University. This may be due to the students learning needs and the large number of extracurricular tasks assigned to them. Regarding self-learning, there is an obvious convergence in ratios between Cihan and the Lebanese French universities, which reflects the great congruence in their educational systems. However, the results of Ishik and alHayat universities were a sign of desire shortage by their students in the use of e-learning for self-learning, which may be highly influential on students during their study period. Regarding social media, Cihan and the Lebanese French universities scored high ratio. This may explain the desire factor and the time available for students as well as the students' attitudes to learn through social media. Regarding the ratios of online materials, it is evident that Ishik University scored the lowest among the other universities. This may be due to the high pressure imposed by the education system on students during their study period. However, the other comparable universities scored low ratios to a certain extent due to various existing limitations. With respect to the purposes of using e-learning in all universities, the results are highlighted in Table 4 and Fig. 4.

Table 4. The purposes of using e-learning in all universities.

\begin{tabular}{|c|l|c|}
\hline$\#$ & Purposes & Ratios \\
\hline 1 & Self-Learning & $53 \%$ \\
\hline 2 & Social Media & $36 \%$ \\
\hline 3 & Extracurricular Activities & $28 \%$ \\
\hline 4 & Classroom Activities & $26 \%$ \\
\hline 5 & Online Materials & $23 \%$ \\
\hline
\end{tabular}

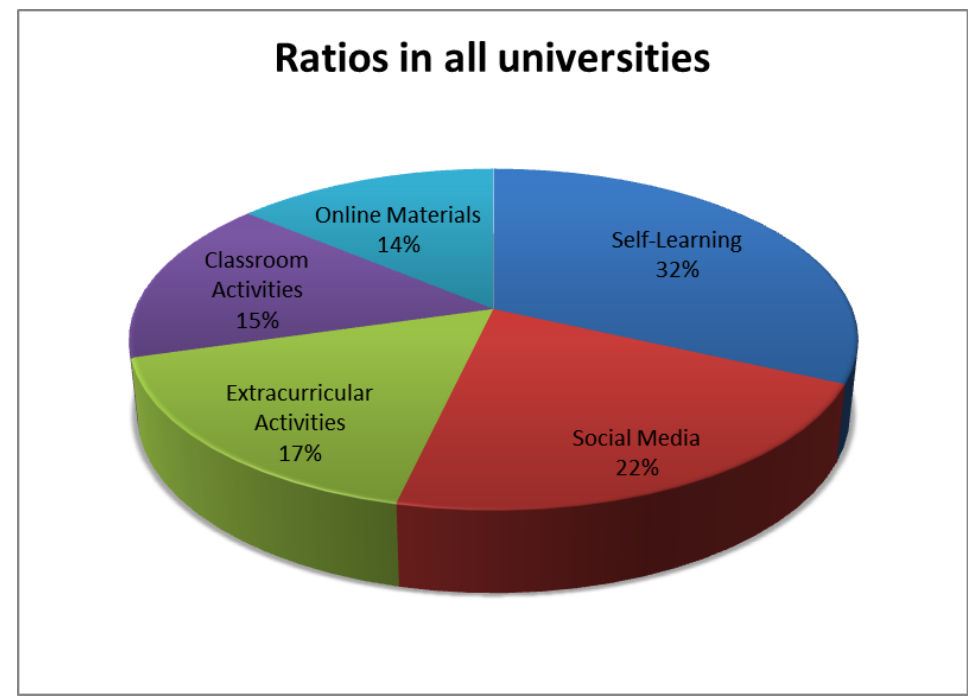

Fig.4. The analytical chart of Table 4.

Table 5. The use of subordinate applications with e-learning.

\begin{tabular}{|c|l|c|c|c|c|}
\hline \multirow{2}{*}{ Subordinate Applications } & \multicolumn{4}{|c|}{ Universities / Ratios } \\
\cline { 3 - 6 } & LFU & Cihan & Ishik & al-Hayat \\
\hline 1 & Calculating the annual grades & $44 \%$ & $44 \%$ & $32 \%$ & $72 \%$ \\
\hline 2 & Creating a class timetable & $40 \%$ & $32 \%$ & $32 \%$ & $4 \%$ \\
\hline 3 & Calculating the attendance & $28 \%$ & $5 \%$ & $5 \%$ & $11 \%$ \\
\hline
\end{tabular}




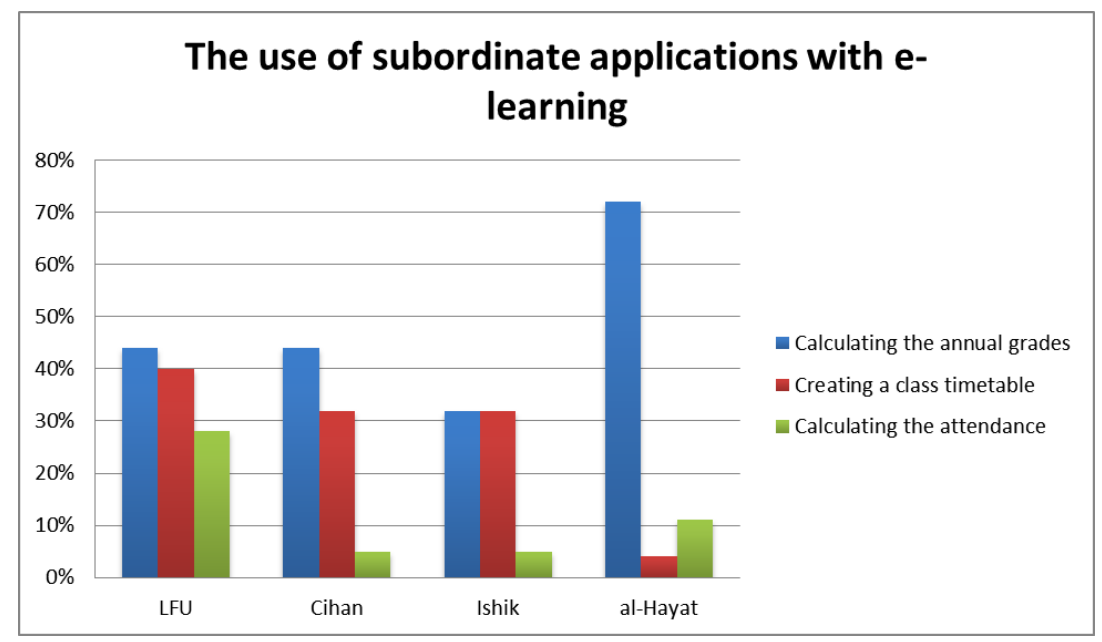

Fig.5. The analytical chart of Table 5.

With respect to the third aspect which involves questions on the use of subordinate applications with the process of e-learning, the results came out as in Table 5 and Fig. 5. As seen from Table 5 and Fig. 5, the students of al-Hayat University scored the highest in using applications that calculate the annual grades, while the students of Cihan and the Lebanese French Universities scored acceptable ratios in such activity. In terms of creating a class timetable, it can be seen that there is convergence among the first three universities, which may be due to the high importance of this issue and the continuous follow-up regarding this subject in those universities. Concerning the calculation of the attendance, all universities scored low ratios except for the Lebanese French University. This may be due to the large number of students' absence on the one hand, and the continuous monitoring by the administration on the other hand. With respect to the used subordinate applications with elearning in all universities, the results are illustrated in Table 6 and Fig. 6.

Table 6. The used subordinate applications with e-learning in all universities.

\begin{tabular}{|c|l|c|}
\hline$\#$ & Subordinate Applications & Ratios \\
\hline 1 & Calculating the annual grades & $48 \%$ \\
\hline 2 & Creating a class timetable & $27 \%$ \\
\hline 3 & Calculating the attendance & $12 \%$ \\
\hline
\end{tabular}

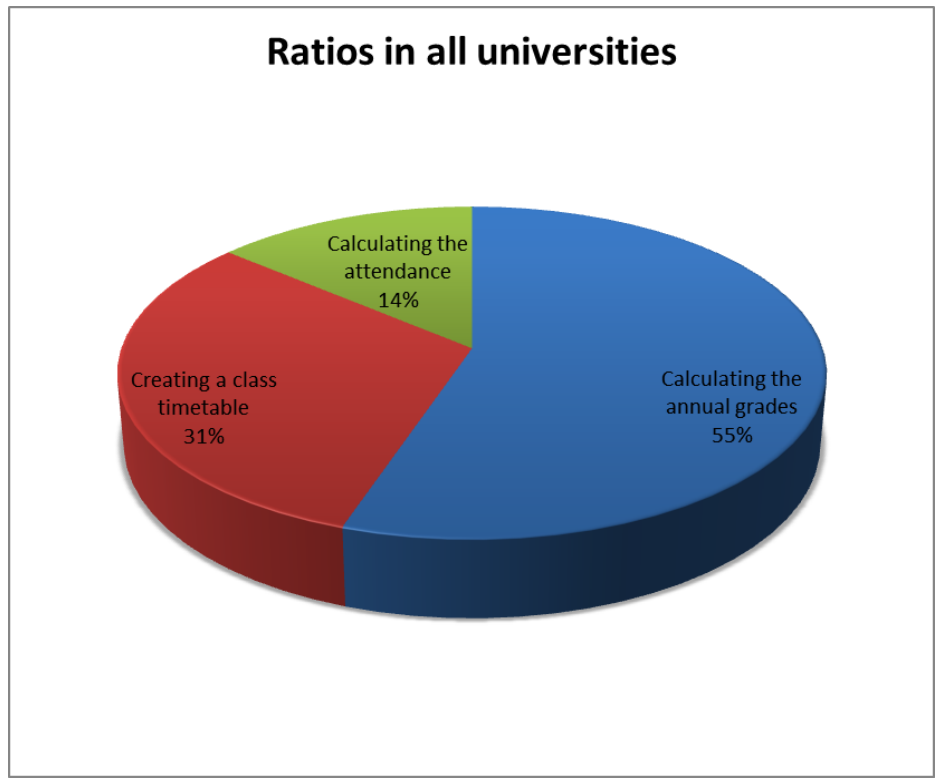

Fig.6. The analytical chart of Table 6. 
From the obtained results, it is apparent that there is an obvious convergence between Cihan and the Lebanese French universities in many aspects. This may be because both universities are using similar educational systems. However, a huge difference is also observed between alHayat and Ishik universities, since they use totally different educational systems. Concerning the first aspect, it was observed that the learners preferred laptops over desktops. As for the tablet computers and smart phones, the increased use of smart phones over tablet computers was perceived.

As for smart boards, they were nonexistent in more than one university. Therefore, the researchers recommend the following: first, the formulation of an efficient educational program that encourages students to use tablet computers, because it combines the characteristics of a computer and a smartphone. Second, the importance of smart boards should be highlighted and activated prominently in their academic curriculums. Concerning the second aspect, it was recognized that the use of e-learning in the classroom together with the extracurricular activities was considerably low. As for learning by means of online materials and social media, the ratios were somewhat unevenly low, but they are in favor of the latter.

As for self-learning, it scored the highest compared with its counterpart. Therefore, the researchers recommend the following: first, the need to reconsider the e-learning programs regarding classroom and extracurricular activities due to their important role in the educational process. Second, it is important to educate students to focus on learning through online materials, because of the rapidity in accessing modern information. Concerning the third aspect, the results are acceptable to some extent. However, it is recommended to increase the use of subordinate applications due to their perceptible usefulness in the e-learning process.

\section{CONCLUSION}

This study explores the application of e-learning at private universities in the Kurdistan region of Iraq. The findings of this study were derived from questionnaires conducted on various students from four different private universities. The researchers selected the private universities because they play a significant role in education; such institutions have supplied the educational systems and allow the adoption of e-learning easily. Hence, the use of tablet computers and smart boards in the e-learning process should be enhanced. Moreover, the e-learning process should be utilized more appropriately with classroom and extracurricular activities. In addition, the use of subordinate applications with the e-learning process should be improved. Finally, the researchers believe that the adoption of e-learning by private universities in Kurdistan region is a process that can be managed easily. Likewise, the adoption of such study in public universities is achievable.

\section{ACKNOWLEDGMENT}

The authors would like to thank the esteemed reviewers for their constructive comments.

\section{REFERENCES}

[1] F. Azhari and L. Ming, "Review of e-learning Practice at the Tertiary Education level in Malaysia", Indian Journal of Pharmaceutical Education and Research, vol. 49, no. 4, pp. 248-257, 2015.

[2] D. Zhang, J. Zhao, L. Zhou and J. Nunamaker, "Can elearning replace classroom learning?", Communications of the ACM, vol. 47, no. 5, pp. 75-79, 2004.

[3] J. Moore, C. Dickson-Deane and K. Galyen, "e-Learning, online learning, and distance learning environments: Are they the same?", The Internet and Higher Education, vol. 14, no. 2, pp. 129-135, 2011.

[4] A. Sife, E. Lwoga, and C. Sanga, "New technologies for teaching and learning: Challenges for higher learning institutions in developing countries", International Journal of Education and Development using Information and Communication Technology, vol. 3, no. 2, pp. 57-67, 2007.

[5] T. Aung and S. Khaing, "Challenges of Implementing eLearning in Developing Countries: A Review", In Genetic and Evolutionary Computing, pp. 405-411. Springer International Publishing, 2015.

[6] J. Leem and B. Lim, "The current status of e-learning and strategies to enhance educational competitiveness in Korean higher education", The International Review of Research in Open and Distributed Learning, vol. 8, no. 1, pp. 1-18, 2007.

[7] C. Goi and P. Ng, "E-learning in Malaysia: Success factors in implementing e-learning program", International Journal of Teaching and Learning in Higher Education, vol. 20, no. 2, pp. 237-246, 2009.

[8] I. Qureshi, K. Ilyas, R. Yasmin, and M. Whitty, "Challenges of implementing e-learning in a Pakistani university", Knowledge Management \& E-Learning: An International Journal, vol. 4, no. 3, pp. 310-324, 2012.

[9] J. Kakbra and H. Sidqi, "Measuring the Impact of ICT and E-learning on Higher Education System With Redesigning and Adapting MOODLE System in Kurdistan Region Government, KRG-Iraq." In Proceedings of the 2 nd $e$ learning Regional Conference-State of Kuwait, vol. 1, pp. 1-10. 2013.

[10] M. Headar, N. Elaref and O. Yacout, "Antecedents and Consequences of Student Satisfaction with e-Learning: The Case of Private Universities in Egypt", Journal of Marketing for Higher Education, vol. 23, no. 2, pp. 226257, 2013.

[11] S. El-Seoud, I. Taj-Eddin, N. Seddiek, P. Ghenghesh, and M. El-Khouly. "The Impact of E-Learning on Egyptian Higher Education and its Effect on Learner's Motivation: A Case Study", Computer Science and Information Technology, vol. 2, no. 3, pp. 179-187, 2014.

[12] D. Phillips, "Comparative Education: method", Research in Comparative and International Education, vol. 1, no. 4, pp. 304-319, 2006.

[13] W. Al-rahmi, M. Othman and L. Yusuf, "The Effectiveness of Using E-Learning in Malaysian Higher Education: A Case Study Universiti Teknologi Malaysia", Mediterranean Journal of Social Sciences, vol. 6, no.5, pp. 625- 637, 2015.

[14] G. Bereday, "Reflections on Comparative Methodology in Education, 1964 - 1966", Comparative Education, vol. 3, no. 3, pp. 169-187, 1967. 
[15] J. Kidd, "Comparative Adult Education: The First Decade". In C. Bennett, J. Kidd and J. Kulich, Comparative Studies in Adult Education: An Anthology, pp. 5-24, 1975, Syracuse, USA: Syracuse University Publications in Continuing Education.

\section{Authors' Profiles}

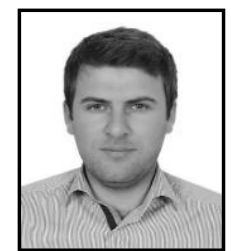

Adnan Fadhil was born in 1983. He received his B.Sc. degree in Educational and Psychological Sciences from the College of Education, University of Mosul in 2006. Then, he received his M.A. in Educational Sciences from the College of Education, University of Mosul in 2009. His research interests include comparative field studies, comparative education and comparative methodologies. Currently, he is serving as the Head of General Education Department at the Lebanese French University. Finally, he has participated in various local and regional conferences, authored many scientific articles and published an academic book in the field of comparative education.

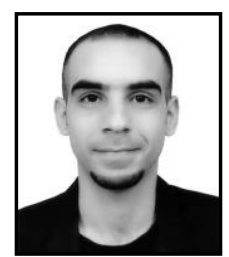

Zohair Al-Ameen was born in $1985 . \mathrm{He}$ received his BSc degree in Computer Science from the University of Mosul in 2008. Then, he received his MSc and $\mathrm{PhD}$ degrees in Computer Science from the Technological University of Malaysia in 2011 and 2015, respectively. He was awarded the best student award due to the outstanding performance in his $\mathrm{PhD}$ studies. His research interests include algorithms design, artificial intelligence, computer forensics, computer vision, digital image processing, information technology and research methodologies. Currently, he is working as a full-time lecturer at the Department of General Education, the Lebanese French University. He has authored many articles which are published in international journals of high repute.

How to cite this paper: Adnan Fadhil, Zohair Al-Ameen,"E-Learning at Private Universities in Kurdistan Region: A Comparative Field Study", International Journal of Modern Education and Computer Science(IJMECS), Vol.8, No.9, pp.35-42, 2016.DOI: 10.5815/ijmecs.2016.09.05 